REVISTA X, Curitiba, volume 14, n.3,251-274, 2019.

\title{
“PASSAR A VISÃO”: REFLEXÕES SOBRE ACOLHIMENTO PELO ENSINO DO PORTUGUÊS DO BRASIL A REFUGIADOS ${ }^{1}$
}

\author{
"Pass the Vision": Reflections on Welcoming by the Teaching of the Portuguese of \\ Brazil to Refugees
}

\section{Sabrina Sant'Anna RIZENTAL (IEL-UNICAMP) ${ }^{2}$}

RESUMO: O presente artigo tem por objetivo traçar um histórico do projeto desenvolvido pela Cáritas RJ e pela Universidade do Estado do Rio de Janeiro (UERJ), cuja principal finalidade é oferecer o ensino de português a falantes de outras línguas que se encontram em situação de deslocamento dito enquanto forçado ou necessário. Este trabalho focaliza a experiência de utilização de uma unidade do material didático desenvolvido para o curso, discutindo os efeitos de sentidos movimentados a partir dessa atividade. O diálogo aqui empreendido procura se alinhar à perspectiva Indisciplinar da Linguística Aplicada, de modo a dar maior visibilidade - ou "passar a visão" - sobre um trabalho que vem sendo direcionado aos solicitantes de refúgio e aos que se encontram na condição de refugiados na cidade do Rio de Janeiro. As análises serão realizadas considerando o conceito de Interculturalidade, conforme discutido por Maher (2007).

PALAVRAS-CHAVE: Ensino de português; Refugiados; Sentidos.

ABSTRACT: The present article aims to outline a history of the project developed by Caritas RJ and the University of the State of Rio de Janeiro (UERJ), whose main purpose is to provide Portuguese teaching to speakers of other languages that are in a situation of "displacement said while forced or necessary". This paper focuses on the experience of using a didactic unit of the material developed for the course, discussing the effects of senses moved from this activity. The dialogue undertaken here seeks to align with the Indisciplinary perspective of Applied Linguistics in order to give greater visibility - or "pass the vision" - about work that has being directed to refugee seekers and to those who are refugees in the city of Rio de Janeiro. The analyzes will be carried out considering the concept of Interculturality, as discussed by Maher (2007).

KEYWORDS: Portuguese teaching; Refugees; Senses.

\footnotetext{
${ }^{1}$ No contexto deste artigo, o significante refugiado abrange não somente os refugiados propriamente ditos, mas também os solicitantes de refúgio, haja vista a nossa constatação empírica da irrelevância de tal distinção no que diz respeito ao objeto do presente trabalho.

${ }^{2}$ Doutoranda no Programa de Pós-Graduação em Linguística do Instituto de Estudos da Linguagem da Universidade Estadual de Campinas. Professora voluntária no curso de português do Programa de Atendimento à Refugiados e Solicitantes de Refúgio da Cáritas RJ. Email: sabrina.santanna.k@gmail.com
} 
REVISTA X, Curitiba, volume 14, n.3,251-274, 2019.

\section{INTRODUÇÃO}

No dia 19 de junho de 2018, o Alto Comissariado das Nações Unidas para Refugiados (ou Agência da ONU para Refugiados) (ACNUR) divulgou seu mais recente $^{3}$ relatório anual, Tendências Globais ${ }^{4}$, referente ao ano de 2017, informando números que mostram "um retrato das migrações forçadas em todo o mundo, resultado de perseguição, conflito ou violência generalizada" (EBC, 2018 ${ }^{5}$ ). De acordo com o relatório, o número de pessoas que deixaram seus países para fugir das violações aos direitos humanos "corresponde a 2,9 milhões a mais do que em 2016 e é o maior aumento que o ACNUR já registrou em um único ano" (ACNUR, 2018 ${ }^{6}$ ).

Os processos migratórios sempre existiram, motivados por inúmeras questões. Contudo, nos últimos anos, o aumento dos deslocamentos, especialmente aqueles compreendidos como forçados, tem sido crítico. Tal aumento vem sendo, a cada ano ${ }^{7}$, amplamente enfocado pela mídia, em pesquisas acadêmicas, em relatórios institucionais. No ano de 2017, foram registradas, de acordo com o relatório Tendências Globais, 16,2 milhões de pessoas que se deslocaram "tanto pela primeira vez como repetidamente - o que corresponde a 44,5 mil pessoas sendo forçosamente deslocadas a cada dia (ou uma pessoa deslocada a cada dois segundos)" (ACNUR, 2018 - itálicos nossos). Essas pessoas continuam deixando seus países, abandonando o lugar onde construíram suas histórias e, em alguns casos, deixando sua própria família para trás, para lutarem por seus direitos básicos, por liberdade e uma vida digna, mesmo que essa escolha as deixe "expostas a situações de instabilidade e incerteza enquanto se deslocam" (RIZENTAL, 2017, p. 22).

\footnotetext{
${ }^{3}$ Esclarecemos que esses relatórios são publicados no site da ONU pouco antes do Dia Mundial do Refugiado, celebrado em 20 de junho, e costumam se referir às informações registradas sobre o ano anterior ao de sua publicação. Ou seja, o relatório mais recente ao qual nos referimos até o momento da finalização deste artigo (março de 2019) foi publicado no dia 19 de junho de 2018 e se refere aos dados coletados até dezembro de 2017. O documento que apresentará informações sobre o ano de 2018 será publicado em junho de 2019.

${ }^{4}$ Global Trends, cujo arquivo pode ser baixado em PDF diretamente do site do ACNUR, nas versões inglês e espanhol, com o título Tendencias Globales.

${ }^{5}$ Disponível em: http://agenciabrasil.ebc.com.br/internacional/noticia/2018-06/numero-de-refugiadosbate-novo-recorde-e-atinge-685-milhoes. Acesso em: 21/01/2019.

${ }^{6}$ Disponível em: https://www.acnur.org/portugues/2018/06/19/mais-de-68-milhoes-de-pessoasdeslocadas-em-2017-e-essencial-um-novo-acordo-global-sobre-refugiados/. Acesso em: 21/01/2019. ${ }^{7}$ No site do ACNUR encontramos várias edições do relatório Tendências Globais (Global Trends). Entretanto, é a partir da edição de 2009 que começam a ser registrados os dados específicos sobre o Brasil.

Disponível em: https://www.unhcr.org/statistics/country/4c11f0be9/2009-global-trends-refugees-asylumseekers-returnees-internally-displaced.html. Acesso em: 21/01/2019.
} 
REVISTA X, Curitiba, volume 14, n.3,251-274, 2019.

Direcionando-se também ao Brasil, os protagonistas desses deslocamentos se arriscam para reconstruir a vida nesse lugar distante, muitas vezes "apoiados num imaginário" (id.) de boa acolhida, construído a partir dos discursos que circulam sobre esse país, apesar de seus costumes distintos e idioma estranho para muitos imigrantes. Com base em divulgação do relatório "Refúgio em Números", feita pelo CONARE ${ }^{8}$, o Brasil reconheceu "um total de 10.145 refugiados de diversas nacionalidades", dos quais "apenas 5.134 continuam com registro ativo no país, sendo que 52\% moram em São Paulo, $17 \%$ no Rio de Janeiro e $8 \%$ no Paraná. Os sírios representam 35\% da população refugiada com registro ativo no Brasil" (ACNUR, 2018 ${ }^{9}$ ). Em relação aos pedidos de refúgio, a mesma página indica que:

No total, 33.866 pessoas solicitaram o reconhecimento da condição de refugiado no Brasil em 2017. Os venezuelanos representam mais da metade dos pedidos realizados, com 17.865 solicitações. Na sequência estão os cubanos (2.373), os haitianos (2.362) e os angolanos (2.036). Os estados com mais pedidos de refúgio são Roraima (15.955), São Paulo (9.591) e Amazonas (2.864), segundo dados da Polícia Federal. (id.).

Esses são os números mais recentes indicados pelo ACNUR, correspondentes até o período final de 2017. Contudo, foi a partir de 2013, com o registro de 17.631 pedidos de refúgio, que o Brasil começou a vivenciar esse aumento, registrando, em 2014 e 2015, o ápice das solicitações, com 28.385 e $28.670^{10}$ pedidos respectivamente.

Naqueles anos, algumas instituições governamentais, tais como a Cáritas $\mathrm{RJ}^{11}$, recebiam verbas do CONARE e do Ministério da Justiça para administrar projetos que atendessem às necessidades básicas desse público. Com o aumento do fluxo de migrantes e de sua chegada no Brasil, tanto em capitais como São Paulo, Rio de Janeiro, Curitiba, quanto em cidades do interior desses e de outros estados, instituições não governamentais passaram a atuar em projetos direcionados ao acolhimento de solicitantes de refúgio e de refugiados. Entre as atividades oferecidas, os cursos de português ganharam corpo e surgiu outra necessidade, a de se pensar o ensino da língua especificamente para esse contexto.

\footnotetext{
${ }^{8}$ Comitê Nacional para os Refugiados.

${ }^{9}$ Disponível em: https://www.acnur.org/portugues/dados-sobre-refugio/dados-sobre-refugio-no-brasil/ . Acesso em: 22/01/2019.

${ }^{10}$ Disponível em: https://www.acnur.org/portugues/wp-content/uploads/2018/01/refugio-em-numeros2010-2016.pdf . Acesso em: 23/01/2019.

${ }^{11}$ Cáritas Arquidiocesana do Rio Janeiro. Disponível em: http://www.caritas-rj.org.br/quem-somos.html. Acesso em: 26/01/2019.
} 
Em São Paulo, uma das cidades do Brasil que oferece o ensino de português para migrantes e refugiados:

[...] um mapeamento realizado em 2015 pela Secretaria de Cidadania da Prefeitura de São Paulo indicou a existência de 15 organizações da sociedade civil, em forma de pastorais, coletivos e organizações de migrantes e ONGs dispondo-se a ensinar a língua portuguesa à população migrante da cidade (BIZON e CAMARGO, 2018, p. 718).

O Rio de Janeiro não se difere de São Paulo no que diz respeito às ações direcionadas ao "ensino da língua portuguesa para migrantes e refugiados" (ibid., p. 723). Na capital carioca essas ações também se encontram "nas horizontalidades, onde a ação do Estado é limitada, havendo, ainda, o protagonismo de agentes da sociedade civil e do voluntariado" (id.). "As horizontalidades - ou espaço banal -" as quais se referem Bizon e Camargo:

[...] são representadas pelas vivências, pelo entorno, ou seja, pelas pessoas em suas agências cotidianas. Nesses espaços, há uma variedade de racionalidades e tempos, permitindo que as produções sejam voltadas aos interesses locais e realizadas dentro de uma área que também constitui um fator de produção. [...] as horizontalidades criam formas de convivência e de regulação a partir do próprio espaço, por meio de microagências, que podem mudar a realidade (ibid., p. 716).

Considerando o cenário descrito, o presente artigo focaliza um projeto desenvolvido pela Cáritas RJ e pela Universidade do Estado do Rio de Janeiro (UERJ), que tem como objetivo central disponibilizar o ensino de português a falantes de outras línguas, moradores da cidade do Rio de Janeiro em situação de deslocamento dito enquanto necessário ou forçado ${ }^{12}$ - seja esse deslocamento motivado por causas naturais ou por razões que justifiquem juridicamente a solicitação de refúgio. Vale frisar que a Cáritas RJ tem longa atuação no ensino de português para refugiados e, em 2015, buscou parceria com a UERJ para a elaboração de materiais didáticos a serem utilizados no curso de português.

Mais especificamente, o objetivo deste trabalho é traçar um histórico do referido projeto, focalizando a experiência de utilização de uma unidade do material didático desenvolvido para o curso e discutindo os efeitos de sentidos movimentados a partir

12 Ao optar pela formulação "deslocamento dito enquanto necessário ou forçado" em vez de, por exemplo, "deslocamento necessário ou forçado", consideramos a discursividade desse dizer e o formulamos de maneira a não estabilizar os sentidos, já que alguns refugiados demonstram desconforto com as designações deslocado necessário e deslocado forçado. Por isso, levamos em conta a forma como os refugiados (não) se dizem. Em boa parte dos casos, eles não dizem que fugiram, não se significam pela fuga, mas sim pela escolha de sair rumo a outro país em vez de deslocar-se internamente com familiares e amigos que se recusaram a abandonar o país de origem. 
REVISTA X, Curitiba, volume 14, n.3,251-274, 2019.

dessa atividade. É importante registrar que o material que analisamos neste artigo foi trabalhado antes de sua publicação, como uma das atividades de um material completo, e que o propósito de sua utilização prévia foi justamente avaliá-lo para posterior publicação. Os registros - anotações de campo registradas em relatórios de acompanhamento - foram gerados pela autora deste artigo, pesquisadora que também atua como professora voluntária de português para refugiados ${ }^{13}$ no curso em tela.

O diálogo aqui empreendido procura se alinhar à perspectiva Indisciplinar da Linguística Aplicada, de modo a dar maior visibilidade - ou "passar a visão" - sobre um trabalho, entre outros trabalhos, que vem sendo direcionado ao ensino de português do Brasil para solicitantes de refúgio e refugiados. Nesse caso, referimo-nos aos refugiados que vivem na cidade do Rio de Janeiro. Analisaremos a atividade realizada com a unidade didática considerando primordialmente o conceito de interculturalidade na perspectiva de Maher, pensando como os sentidos se movimentam nesse esforço de diálogo entre "conhecimentos e comportamentos construídos sob bases culturais distintas e frequentemente conflitantes" (MAHER, 2007, p. 258). Ao longo do texto, proporemos reflexões amparadas também em outros autores que dedicam atenção às questões relacionadas ao ensino de línguas. Acreditamos que, com esse foco, possamos contribuir para que essas experiências em sala de aula também inspirem o afinamento de materiais para fins específicos nesse contexto de ensino de português.

Vale esclarecer que "passar a visão" significa dizer o que está acontecendo no entorno. Trata-se de uma expressão utilizada em comunidades da cidade do Rio de Janeiro. Expressão de uma região específica de um país como o Brasil, “considerado país da diversidade por excelência, complexo não apenas do ponto de vista sociogeográfico, como também do ponto de vista humano" (CORACINI, 2013[2007], p. 79). Em 2017, essa expressão ficou mais evidenciada como bordão do personagem Sabiá da telenovela brasileira chamada "A força do querer"14, que foi produzida pela Rede Globo e exibida no horário nobre. Entretanto, muito antes da popularização desse personagem, esse bordão já circulava na sala de aula da qual falaremos, surgindo como

\footnotetext{
13 A pesquisadora trabalha como voluntária na Cáritas RJ desde 2015, quando iniciou suas atividades no projeto de arteterapia direcionado às crianças que se encontravam em situação de refúgio no Rio de Janeiro. Após um mês realizando esse trabalho, a pesquisadora recebeu sua primeira turma do curso de português e então passou a atuar no projeto de arteterapia e no curso de português concomitantemente. Em 2016 o projeto de arteterapia foi descontinuado e a pesquisadora permaneceu atuando apenas como professora do curso de português que segue ativo até o atual momento.

14 JUNQUEIRA, C. Disponível em: https://www.vix.com/pt/tv/551263/vou-passar-a-visao-como-sabiase-tornou-tao-popular-dentro-e-fora-da-novela. Acesso em: 26/12/2017.
} 
REVISTA X, Curitiba, volume 14, n.3,251-274, 2019.

uma pergunta surpreendente até mesmo para a pesquisadora e professora voluntária do curso de Português para Refugiados organizado pela Cáritas RJ: "Professora, o que é 'passar a visão'? ${ }^{15}$ ". Neste artigo "passar a visão" significa mostrar um trabalho que vem sendo realizado há tempos, mas que, nos últimos quatro anos, vem ganhando novos contornos.

Esse artigo se estrutura em cinco seções, além desta introdução e das considerações finais. Na primeira, apresentamos o trabalho da Cáritas RJ, no que diz respeito ao ensino de português para refugiados. Na segunda, expomos a iniciativa da UERJ na elaboração do material do curso de português. Na terceira, explicamos a estrutura e o funcionamento do curso e, na quarta seção, explicamos como são registradas as atividades realizadas durante as aulas. Finalmente, na quinta seção, analisamos os efeitos de uma unidade didática utilizada antes da publicação do material. Iniciamos, então, abrindo as portas da Cáritas.

\section{CÁRITAS DE PORTAS ABERTAS}

Em 2015, em um evento chamado "Cáritas de Portas Abertas", a pesquisadora, autora desse artigo, teve a oportunidade de conhecer os projetos direcionados pela instituição aos refugiados que chegavam à cidade do Rio de Janeiro. No encontro, aberto ao público e realizado na sede da instituição, representantes da Cáritas RJ discorriam sobre o funcionamento do Programa de Atendimento a Refugiados e Solicitantes de Refúgio, atualmente denominado PARES, esclareciam dúvidas sobre o sistema brasileiro de proteção e as iniciativas de apoio, e abriam espaço para perguntas - nesse momento contando também com a participação de refugiados, apoiados pela instituição, que eram convidados a falar sobre sua experiência pessoal no Rio de Janeiro. Geralmente, eles acabavam contando um pouco da sua história de vida e falando sobre o processo de deslocamento. Na maioria dos casos, os refugiados que se pronunciavam nesse evento já participavam há algum tempo do curso de português oferecido pela instituição. Foi nessa ocasião que a pesquisadora conheceu melhor o trabalho da Cáritas RJ e solicitou a oportunidade de fazer parte do grupo de voluntários que vinha auxiliando nos projetos desenvolvidos pela instituição.

${ }^{15}$ A pergunta foi feita à professora voluntária dentro da sala de aula do curso de português oferecido pela Cáritas RJ, em um ambiente no qual os refugiados se sentem seguros. Por isso, preservaremos a identidade do estudante. 
REVISTA X, Curitiba, volume 14, n.3,251-274, 2019.

Em relação ao ensino de português, a Cáritas RJ tem longo histórico de atuação junto aos refugiados. Entretanto, o início dessa atividade se deu de forma mais rudimentar, num momento em que as aulas eram ministradas em espaços improvisados, mas que contavam com a presença de um número razoável de participantes, como lemos nos seguintes trechos que destacamos de duas reportagens:

\begin{abstract}
Mesmo com o calor registrado nos primeiros dias de março, crianças e adultos, em sua maioria provenientes da República Democrática do Congo, lotavam a varanda transformada em sala de aula para aprender as primeiras palavras da língua do país que os acolheu. (BBC Brasil, 2013 ${ }^{16}$ - itálicos nossos).
\end{abstract}

A reportagem do Portal acompanhou aulas de português para refugiados, na varanda da casa transformada em sede carioca da Cáritas. Ali, cerca de 30 estrangeiros de diversas nacionalidades aprendem a nossa língua e passagens marcantes da nossa história, da nossa cultura. (IKMR, 2013 ${ }^{17}$ - itálicos nossos).

$\mathrm{Na}$ época em que essas reportagens foram publicadas, a Cáritas RJ se preocupava em prover cursos básicos de português para que refugiados pudessem administrar situações cotidianas, tais como mobilidade urbana, entrevistas para a obtenção da condição de refugiado, diálogos com advogados e assistentes sociais, entrevistas de trabalho, encaminhamento às unidades de saúde públicas, matrícula das crianças refugiadas nas escolas públicas, entre outras situações.

Em 2015, quando a pesquisadora iniciou suas atividades como professora voluntária no ensino de português, cada refugiado cadastrado na Cáritas RJ tinha direito a frequentar o curso durante um ano e as aulas eram ministradas nas salas de uma igreja próxima da sede da Cáritas $\mathrm{RJ}^{18}$ por voluntários que, em sua maioria, não eram professores, mas pessoas que tinham disponibilidade de tempo e falavam uma ou mais línguas além do português.

$\mathrm{Na}$ época, as línguas mais prestigiadas pela Cáritas, em sua seleção de voluntários, eram o inglês e o francês, uma vez que a instituição cadastrava um alto número de imigrantes procedentes de países da África, tais como Nigéria, Etiópia, Uganda, onde o inglês é uma das línguas oficiais, e da República Democrática do Congo, país onde o francês é uma das línguas oficiais. Essas línguas - o inglês e o

\footnotetext{
${ }^{16}$ Disponível em: https://www.bbc.com/portuguese/celular/noticias/2013/03/130311_refugiados_depoimentos_cq.shtml. Acesso em: 17/03/2015.

${ }^{17}$ Disponível em: http://www.ikmr.org.br/2013/12/em-busca-de-paz-e-emprego-refugiados-somam-5mil-no-brasil/. Acesso em: 17/03/2015.

${ }^{18}$ A Cáritas RJ está situada no bairro do Maracanã, na cidade do Rio de Janeiro, na mesma rua onde também está localizada a UERJ.
} 
REVISTA X, Curitiba, volume 14, n.3,251-274, 2019.

francês - cumpririam a função de línguas mediadoras durante as aulas, caso fosse necessário.

Os materiais didáticos utilizados até o início de 2016 eram fornecidos pelos próprios professores voluntários, que os elaboravam a partir de materiais diversos para o ensino de português para estrangeiros disponibilizados na internet. Além disso, havia uma apostila disponibilizada pela Cáritas RJ, sem autoria explicitada, de base marcadamente estruturalista, que também servia de apoio a alguns professores voluntários no preparo de seus materiais.

Desde essa época, a Cáritas RJ buscava parcerias com instituições de ensino que pudessem contribuir com a elaboração de materiais didáticos a partir de bases teóricas mais contemporâneas, e que fossem mais específicos ao ensino de português para o contexto de refúgio. Também havia uma expectativa dos professores voluntários pelo material, uma vez que, como a maioria não tinha formação docente, eles diziam crer que com o material as aulas fluiriam de maneira mais produtiva. Ao analisar as questões relacionadas aos materiais didáticos e a relação dos professores com esses materiais na condução de cursos de Português como Língua de Acolhimento, Lopez (2016, p. 160) explica que "para os professores, a importância do material didático tem relação com fins mais práticos, de soluções imediatas para questões em sala de aula" e acrescenta que:

[...] os professores consideram o material didático um apoio que serviria para tirar ideias, sanar suas dúvidas quanto ao conteúdo que deve ser ensinado e a progressão das aulas, bem como seria uma fonte que apontaria para necessidades específicas do público-alvo (LOPEZ, 2016, p. 161).

A autora adverte, no entanto, que:

[...] há que se ter cuidado ao adotar um livro didático, porque ele pode apresentar algumas desvantagens, dentre as quais: podem apresentar conteúdo pouco relevante e/ou descontextualizado para o público-alvo, podem exercer um controle implícito sobre os professores (id.).

Nas palavras de Diniz, Stradiotti e Scaramucci (2009, p. 267), o livro didático "pode funcionar como principal, ou mesmo único guia para muitos professores, que, por falta de formação, poderiam, sem o livro, se ver ainda mais desorientados em relação ao ensino." Por isso, em conversa com a pesquisadora e professora voluntária, a coordenadora pedagógica da Cáritas RJ externava sua preocupação com os conteúdos que eram apresentados aos refugiados e considerava bem-vinda a parceria com uma 
REVISTA X, Curitiba, volume 14, n.3,251-274, 2019.

instituição que possibilitasse pensar essas questões. A UERJ, além de ser uma universidade reconhecida no Rio de Janeiro por sua excelência, também oferecia a vantagem de estar localizada a poucos metros da Cáritas RJ e, de acordo com a coordenadora pedagógica, isso também foi pensado no momento de fazer o primeiro contato. A proximidade física facilitaria a logística.

O contato com a UERJ se deu através da Faculdade de Educação, que, por sua vez, se juntou a um grupo de professores do Instituto de Letras da mesma universidade para firmar a parceria com a Cáritas RJ e iniciar o projeto de elaboração dos materiais.

\section{O PORTUGUÊS COMO LÍNGUA DE ACOLHIMENTO E A INICIATIVA DA UERJ}

Tema de discussões em áreas dos Estudos da Linguagem, o campo teórico que se dedica ao ensino de português àqueles que se encontram em situação de refúgio ou a outros tipos de deslocamento dito forçado vem sendo chamado Português como Língua de Acolhimento (PLAc). Mais recentemente, alguns pesquisadores, como Anunciação (2018), Bizon e Camargo (2018), Lopez e Diniz (2018), têm chamado a atenção para a necessidade de se compreender o acolhimento em uma perspectiva que se afaste de um senso comum, que, frequentemente, o concebe de maneira redutora, vinculando-os a ações paternalistas. Nessa redução, o contexto de refúgio é frequentemente representado como um lugar de faltas e lacunas, e o acolhimento, consequentemente, como um projeto de preenchimento dessas lacunas, aproximando-o de políticas assimilacionistas. Em direção contrária a esse reducionismo, os autores supracitados reconhecem a especificidade do contexto de ensino de português e a importância política de se marcar tal especificidade por meio da denominação de uma área específica. Frisam, contudo, a necessidade de se assumir uma visão ampliada de acolhimento, que se afaste da visão de senso comum em que

[...] acolher é dar ao Outro o que ele supostamente necessita, sendo essa necessidade sempre definida a partir do agente "acolhedor". Essa prédeterminação que hierarquiza as relações posiciona o migrante como inferior, diminuindo ou até mesmo interditando a possibilidade de relações efetivamente interculturais e, portanto, mais igualitárias (BIZON; CAMARGO, 2018, p. 715 - aspas das autoras).

Assim, na perspectiva à qual esse artigo se afilia, Português como Língua de Acolhimento (PLAc) é compreendido como 
[...] a ramificação da subárea de Português como Língua Adicional (PLA) integrante, portanto, da área de Linguística Aplicada - que se dedica à pesquisa e ao ensino de português para imigrantes, com destaque para deslocados forçados, que estejam em situação de vulnerabilidade e que não tenham o português como língua materna. Seu objetivo é a produção e circulação de saberes linguístico-discursivos que, em última instância, contribuam para "produzir e democratizar mobilidades e multiterritorialidades", fazendo face a processos de "reterritorialização precária" (BIZON, 2013, p. 123 - aspas da autora). Tais saberes, sublinhamos, podem, facilmente, ser atravessados por um discurso essencialista e totalizador, que significa os imigrantes pela falta e, dessa forma, como sujeitos carentes e dignos de pena. Como argumenta Lopez (2016), tal discurso representa, no limite, a própria interdição da possiblidade de interculturalidade na especialidade de PLAc: os imigrantes deslocados forçados teriam antes o que receber, para suprir suas (supostas) faltas, do que o que compartilhar. Daí a necessidade imperativa de um olhar sempre problematizador, que lance dúvidas sobre certezas que facilmente podem ir se construindo na especialidade em questão. (LOPEZ e DINIZ, 2018, s/p).

Como anteriormente explicitado, desde 2015, a Cáritas RJ buscava universidades parceiras para a preparação dos materiais didáticos. Em março de 2017, com a assinatura de um convênio com o ACNUR para implementação da Cátedra Sérgio Vieira de Mello (CSVM), a UERJ, assim como outras universidades nacionais que também assinaram esse convênio, se comprometeu "a incluir a temática do refúgio dentro de seus programas" (ACNUR, $2017^{19}$ ).

Além de difundir o ensino universitário sobre temas relacionados ao refúgio, a Cátedra também visa promover a formação acadêmica e a capacitação de professores e estudantes dentro desta temática. O trabalho direto com os refugiados em projetos comunitários também é definido como uma grande prioridade. (CENTRO RIO DE SAÚDE GLOBAL, 2017²0).

A partir desse momento, Cáritas RJ e UERJ formalizaram a parceria. Após cerca de um ano de trabalho, em 2018, a UERJ lançou o material intitulado "Entre nós: português com refugiados" (ARANTES (coord.), 2018 ${ }^{21}$ ). O lançamento foi realizado no IX Seminário Nacional da Cátedra Sérgio Vieira de Mello - ACNUR / III Conferência Latino-Americana sobre Refúgio, Migração e Apatridia ${ }^{22}$, na cidade de Curitiba. No texto de apresentação desse material, a UERJ explica que:

Inicialmente dirigida a docentes do Departamento de Jovens e Adultos da Faculdade de Educação, e conectando-se, posteriormente a docentes dos Departamentos de Estudos da Linguagem e de Línguas Anglo-Germânicas do

${ }^{19}$ Disponível em: https://www.acnur.org/portugues/2017/03/16/uerj-e-fundacao-casa-rui-barbosa-sao-asmais-novas-integrantes-da-catedra-sergio-vieira-de-mello/ Acesso em: 15/02/2019.

${ }^{20}$ Disponível em: http://centroriosaudeglobal.org/?page id=1395. Acesso em: 15/02/2019.

21 Disponível em: https://editoracartolina.files.wordpress.com/2019/01/entre nos.pdf. Acesso em: 23/01/2019.

${ }_{22}$ Disponível para consulta em: http://www.ppgd.ufpr.br/wp-content/uploads/2018/09/programacaogts.pdf. Acesso em: 23/01/2019. 
Instituto de Letras da Universidade do Estado do Rio de Janeiro, a solicitação formulada pela Cáritas-RJ continha um contorno particularmente desafiador, qual seja: a chegada de grupos de refugiados com mulheres e crianças e não apenas homens de uma faixa etária específica ampliava diversidade de situações de comunicação, os tipos de preocupações e desejos de expressão e as demandas de acesso aos equipamentos públicos de educação e saúde. Ao lado dessa dimensão mais premente, outros aspectos suscitavam nossa atenção: i) heterogeneidade de formações e experiências formativas trazidas de contextos muito diversos aos nossos; ii) fluxo contínuo de chegadas e, portanto, diversificação do público em cada aula; iii) expectativas com relação à aprendizagem da língua e a inserção na comunidade; iv) grupos falantes de línguas muito diversas. (ARANTES (coord.), 2018, s/p).

Além do material didático, a UERJ passou a disponibilizar salas para as aulas do curso de português, que, como explicamos anteriormente, era realizado nas salas de uma igreja próxima da Cáritas RJ.

\section{O CURSO DE PORTUGUÊS NO MOMENTO ATUAL}

Como já mencionado, a UERJ está localizada a poucos metros da Cáritas RJ e essa proximidade física facilita a logística dos refugiados. Em boa parte dos casos, eles se dirigem à Cáritas RJ antes do início das aulas e de lá seguem junto com a coordenadora pedagógica, responsável também por abrir as salas que estão disponíveis na UERJ. Ao final das aulas, os refugiados retornam à Cáritas RJ e lá recebem ajuda de custo para se deslocarem do Maracanã até os bairros onde residem e retornarem no dia da próxima aula.

As aulas ocorrem duas vezes por semana, às segundas e sextas ou às terças e quintas e o tempo de aula é de 2 horas, das 09 h30 às 11 h30. O curso está organizado a partir de línguas mediadoras da seguinte forma: Francês 1 e 2, Espanhol, Inglês 1 e 2. A intermediação através dessas línguas é feita em caráter estratégico, a fim de facilitar a interação em momentos em que a dificuldade de acesso ao português é muito grande, e sua incidência é mais frequente nas turmas de nível 1, que acolhe solicitantes de refúgio recém-chegados no Brasil. Os professores utilizam diferentes recursos multisemióticos - textos impressos e orais, imagens, objetos - que se materializam em atividades e tarefas que visem promover interação significativa em sala. A nomeação das turmas segue o mesmo raciocínio, isto é, Francês 1 para estudantes falantes de outras línguas, entre elas o francês, que não falam, mal falam ou falam pouco português; Francês 2 para aqueles que já têm razoável conhecimento do português do Brasil ${ }^{23}$, mas precisam ou

\footnotetext{
${ }^{23}$ É importante esclarecer que alguns solicitantes de refúgio conhecem o português de Portugal, como foi o caso de dois estudantes procedentes da Rússia e da Ucrânia, ou de outros países onde também se fala português, como, por exemplo, alguns estudantes vindos de países da África que antes migraram pelo
} 
REVISTA X, Curitiba, volume 14, n.3,251-274, 2019.

querem aperfeiçoá-lo; Espanhol ${ }^{24}$ para os estudantes procedentes de países hispanofalantes; Inglês 1 e 2 para estudantes falantes de outras línguas, entre elas o inglês, seguindo o mesmo raciocínio do francês. Apoiada em Diniz (2019, comentário informal), ressalto que o fato de haver uma nomeação já essencializa, em certa medida, os alunos, apagando outras línguas em favor das línguas oficiais. Este é o caso, por exemplo, dos haitianos que falam francês, mas tem como principal língua o crioulo haitiano ou dos sírios ${ }^{25}$ que, na maioria dos casos, falam árabe e inglês básico.

Mota (2004), ao relatar dois casos em que "a língua inglesa está caracterizada como detentora do poder em uma situação de bilinguismo com o espanhol" (MOTA, 2004, p. 38), propõe “dois diferentes caminhos de análise" (id.) para esses funcionamentos: (i) como uma "pretensa impossibilidade de coexistência" que caracteriza uma situação de "bilinguismo subtrativo", que "é visto como resultado de uma ideologia culturalmente assimilacionista, que reforça atitudes 'linguicistas', em apoio ao posicionamento imperialista da língua inglesa" ( $i b$. - aspas da autora). Nas salas de aula do curso em foco, o estudante que tem como língua principal o crioulo haitiano, o árabe ou o lingala (no caso dos congoleses) terá que se adequar ao aprendizado do português sob a mediação das línguas favorecidas, nesse caso o inglês e o francês, quando essa mediação se fizer necessária; e (ii) como um funcionamento em que há “intenção de coexistência” entre línguas, caracterizando uma situação aditiva, ou de "bilinguismo aditivo". Essa situação "se caracteriza por uma ideologia libertadora, sócio-interacionista, culturalmente sensível, que delega 'empoderamento' aos grupos socialmente excluídos" (id.). Esse conceito se mostra mais em linha com o que consideramos que seja uma das funções da aula de língua adicional, isto é, propiciar o diálogo intercultural que trabalhe além da discussão sobre o diferente que busca o consenso, pois isso estaria vinculado a uma visão redutora de multiculturalismo liberal, que, segundo Maher (2007, p. 260), trivializa as diferenças culturais, celebrando

continente africano passando por países onde o português é uma das línguas oficiais. Em 2017, a turma Inglês 2 do curso oferecido pela Cáritas RJ vivenciou as duas situações.

${ }^{24}$ Em 2018, a turma de Espanhol foi dividida em níveis 1 e 2, como definido pela Cáritas RJ para o francês e o inglês, devido à chegada de grupos de venezuelanos na cidade do Rio de Janeiro. Esses grupos participaram do processo de interiorização organizado pelo governo federal, que os transportou de cidades do estado de Roraima a outros estados. A cidade do Rio de Janeiro recebeu grupos que foram trazidos predominantemente do município de Pacaraima e continua recebendo venezuelanos que, em alguns casos, passam antes por outras cidades do Brasil.

${ }^{25}$ Em relação aos sírios, em 2016 a Cáritas RJ recrutou uma professora voluntária que, entre outras línguas, falava árabe e naquele momento os sírios foram deslocados das turmas Inglês 1 e Inglês 2 para a turma nomeada Árabe, mas essa configuração não durou muito tempo, pois a professora não pôde mais disponibilizar tempo para realizar o trabalho voluntário. 
REVISTA X, Curitiba, volume 14, n.3,251-274, 2019.

"apenas aquilo que está na superfície das culturas (comidas, danças, música), sem conectá-las com a vida real das pessoas e de suas lutas políticas." O que se propõe, como diálogo intercultural, é uma prática que possa colocar a diferença em discussão.

\section{REGISTROS DAS ATIVIDADES}

Essa prática, que tem como base o diálogo intercultural, vem sendo aprimorada ao longo dos últimos anos por todas as pessoas envolvidas no andamento do curso de português oferecido aos solicitantes de refúgio e refugiados pela Cáritas RJ. As iniciativas dos professores voluntários, na interação com os estudantes, e o aprendizado que delas resulta, após a realização das atividades nas salas de aula, vêm sendo devidamente registrados e compartilhados com a coordenação pedagógica da Cáritas RJ.

Desde que iniciou o trabalho como voluntária junto a essa instituição, todas as atividades realizadas pela pesquisadora - tanto na época em que atuou no projeto de arteterapia com as crianças como no curso de português - vêm sendo registradas em Relatórios de Acompanhamento disponibilizados pela coordenadora pedagógica da Cáritas RJ.

No relatório atual ${ }^{26}$ devemos registrar os seguintes itens: dia da semana, turma, data, professor, número de alunos, material utilizado - se próprio, da UERJ, do ACNUR ou outro -, tema da aula, atividade proposta, desenvolvimento da aula, recursos utilizados, participação da turma e observações. O modelo de relatório anterior, utilizado até o final do período letivo correspondente ao segundo semestre de 2018, disponibilizava um campo nomeado "Material UERJ modificado", que indicava um momento em que o material fornecido por essa instituição ainda não tinha sido publicado. Além de disponibilizar os mesmos campos do relatório atual, o relatório anterior também permitia registrar sugestões para a continuidade da atividade por outro professor, uma vez que para as turmas cujas aulas são realizadas nas segundas e sextas há um professor para a segunda e outro para a sexta e da mesma forma se sucede com as aulas ministradas nas terças e quintas, isto é, há um professor diferente para cada dia. Nessa parte do relatório, o professor voluntário indicava onde parou, a recomendação de

\footnotetext{
${ }^{26} \mathrm{O}$ modelo do relatório foi alterado no início do período letivo atual, março de 2019, e está em fase experimental, podendo ser acessado através do link: https://docs.google.com/forms/d/e/1FAIpQLSf9wvhUQpLOYgNDMpGupY2AB7s_pv88Li686ulTsn2bD ZjQnw/viewform
} 
REVISTA X, Curitiba, volume 14, n.3,251-274, 2019.

continuidade e observações que considerasse relevantes. No relatório atual todas essas informações podem ser registradas no campo Observações. Dessa forma, cada professor busca trabalhar alinhado não apenas com o colega com quem divide a mesma turma, mas também com os outros professores voluntários, à medida que haja a necessidade de substituí-los em algum momento.

Em algumas ocasiões, nas quais a pesquisadora, atuando como professora voluntária, precisou substituir colegas que precisaram se ausentar subitamente, a alternativa foi juntar a turma que estava sob sua responsabilidade com a turma do professor ausente ${ }^{27}$. Nem sempre a língua mediadora era a mesma e algumas vezes a pesquisadora - que tem formação, além de português, em espanhol e inglês - trabalhou ao mesmo tempo com os falantes de inglês e os hispano-falantes. Esses momentos são ainda mais desafiadores, na medida em que há questões específicas que emergem ao ensinar português para falantes de línguas africanas ou de outros idiomas, tais como russo, ucraniano, árabe, e outras questões que são levantadas pelos falantes de língua próxima, como é o caso do espanhol. Conforme Ferreira (2019), isso causa "muitos problemas" (UNICAMP, 2019 ${ }^{28}$ ), pois o material elaborado para uma aula de português que será ministrada a falantes de línguas africanas, árabe e inglês se torna "muito fácil" (id.) para os falantes de espanhol. Por isso, há a necessidade de "separar os falantes de Espanhol dos outros falantes, e elaborar um material mais dinâmico que" (id.) atenda "melhor as especificidades desses alunos" (id.).

\title{
EFEITOS DE UMA UNIDADE DIDÁTICA UTILIZADA ANTES DA PUBLICAÇÃO DO MATERIAL
}

Pensando as especificidades dos refugiados que participavam do curso de português, a equipe da UERJ publicou o seguinte esclarecimento na apresentação do material didático elaborado para o ensino de português do Brasil a refugiados:

\begin{abstract}
Encontrávamo-nos diante da necessidade de apresentar textos e, com eles, sentidos, saberes e valores de nossa experiência concreta. Não apenas estruturas linguísticas hierarquizadas, linearizadas, mas enunciados que convocam o outro a tomar posição, diante de situações cotidianas e compartilhar a luta por direitos. Se a impossibilidade de cindir as formas linguísticas das situações de troca verbal das quais emergem nos orientava teoricamente, eticamente é a indivíduos dotados de experiências e de vontade de se expressar e assumir lugares de fala potentes que nos dirigimos (ARANTES (coord.), 2018, s/p).
\end{abstract}

\footnotetext{
${ }^{27}$ Outra opção seria cancelar a aula do professor voluntário que precisou se ausentar em cima da hora, mas isso seria prejudicial aos estudantes.

${ }^{28}$ Disponível em: http://www.unicamp.br/ matilde/entrevista_itacira.html. Acesso em: 16/02/2019.
} 
REVISTA X, Curitiba, volume 14, n.3,251-274, 2019.

Nesse sentido, o material não foi organizado de forma linear. Foi publicado "em fascículos, sem paginação, para possibilitar ao professor e aos alunos um trabalho mais autônomo, que respeite a dinâmica do grupo e suas especificidades" (id.). A opção pela publicação em fascículos está "centrada nas temáticas, não nas estruturas linguísticas, sobretudo para possibilitar maior interação entre os alunos e professores, possibilitando espaço para as trocas interculturais. Cada fascículo está dividido em três partes: i) A Trocando ideias; ii) B - Conhecendo mais; iii) Vivendo melhor." (id.).

O primeiro fascículo se inicia com a "Atividade: Carioquices", que pode ser acessada em: https://editoracartolina.files.wordpress.com/2019/01/entre_nos.pdf. No primeiro semestre de 2017, essa atividade foi disponibilizada para utilização antes da publicação do material na íntegra. A unidade foi entregue aos professores voluntários pela coordenadora pedagógica da Cáritas RJ, para que fosse utilizada em aula na qual fosse possível observar o funcionamento do material, sem, contudo, maiores esclarecimentos sobre o objetivo do referido material.

Em data previamente combinada com a pesquisadora, a unidade foi apresentada aos estudantes do grupo de língua mediadora inglês nível 2, isto é, estudantes falantes de outras línguas, entre elas o inglês, cujo nível de aprendizado do português poderia ser considerado intermediário. Contudo, segundo a coordenadora pedagógica, a unidade teria sido elaborada de tal forma que poderia ser trabalhada em qualquer nível.

No dia da utilização do material didático, o grupo estava formado por cinco nigerianos, um russo, uma sul-africana, um togolês e um ugandense. Foi esclarecido aos estudantes que se tratava de um material experimental e que seus comentários seriam relevantes para que a equipe da UERJ pudesse realizar ajustes a fim de tornar a unidade funcional e adequada aos propósitos do curso.

No relatório de acompanhamento dessa aula, a pesquisadora registrou que, após alguns minutos de grande silêncio durante a introdução da Atividade, a partir da música "Cariocas", da cantora Adriana Calcanhoto ${ }^{29}$, localizada na parte "A - Trocando ideias", do referido material, um estudante togolês foi o primeiro a dizer que não se sentiu à vontade com a letra da canção, em função de sua vivência na interação com os cariocas. Ele declarou que não concordava com os versos que afirmavam que os cariocas eram bonitos, bacanas, dourados, etc. Os outros participantes argumentaram

29 Disponível em: https://www.vagalume.com.br/adriana-calcanhoto/cariocas.html. Acesso em: $25 / 01 / 2018$. 
REVISTA X, Curitiba, volume 14, n.3,251-274, 2019.

que, para eles, os versos "cariocas são sacanas/cariocas são espertos" não produziam sentidos positivos sobre sua vivência na relação com os cariocas, especialmente com os colegas de trabalho. Segundo os estudantes, os cariocas ditos na letra da canção enquanto "sacanas", “espertos" eram, em seu cotidiano, pessoas mentirosas que levavam vantagem sobre os refugiados. Talvez possamos observar aqui três das quatro ${ }^{30}$ premissas da perspectiva que Maher apresenta como Multiculturalismo Crítico ou Interculturalidade: "a realidade é uma construção; as interpretações são subjetivas e construídas discursivamente; e os valores são relativos" (SEMPRINI, 1999, apud MAHER, 2007, p. 265).

Durante a leitura e a análise dos versos "cariocas têm sotaque, cariocas são alegres, cariocas são tão sexys", os estudantes foram provocados a pensar uma construção de realidade diferente daquela que vivenciavam, pois, de acordo com suas argumentações, após a leitura desses versos, os venezuelanos, os ugandenses, os togoleses, os sul-africanos, os russos, os nigerianos, os congoleses também tinham sotaque, mas, como eles diziam, o sotaque desses não cariocas não lhes parecia coincidir com os mesmos efeitos produzidos pela letra da canção. Segundo eles, os sotaques os significavam na diferença, marginalizando-os. Alguns concordaram que em algumas situações, como no ambiente de trabalho, por exemplo, eram inclusive ridicularizados ao tentar falar. Essas manifestações se deram a partir de gestos de interpretação com base na realidade individual desses estudantes, bem como em seus valores, que, com Maher (2007, p. 265), compreendemos serem "relativos" à experiência de vida de cada um.

Outras questões foram formuladas pelo estudante procedente do Togo que participava daquela aula, tais como: “quem participa dessas reuniões ${ }^{31}$ ?", "algum refugiado faz parte desse grupo?" Com a resposta negativa da pesquisadora, na posição de professora voluntária, ele argumentou que seria importante que os estudantes pudessem ao menos ter um representante refugiado nessas reuniões. Esses dizeres foram endossados pelo grupo.

Nesse relatório de acompanhamento, a pesquisadora registrou, no item "reação da turma", entre os aspectos mais relevantes da utilização desse material, a demonstração de estranhamento materializada nas perguntas feitas pelo estudante do

\footnotetext{
${ }^{30}$ As quatro premissas são: a) a realidade é uma construção, b) as interpretações são subjetivas e construídas discursivamente, c) os valores são relativos e c) o conhecimento é um fato político (id.).

${ }^{31}$ Referindo-se às reuniões organizadas pela equipe da UERJ para discutir a elaboração dos materiais.
} 
REVISTA X, Curitiba, volume 14, n.3,251-274, 2019.

Togo e nos comentários dos refugiados: "cariocas são mentirosos"; "cariocas levam vantagem sobre os refugiados". No item "desenvolvimento da atividade proposta", consta que não foi possível completar a "Atividade: Carioquices", mas que os alunos se interessaram especialmente pela questão que apresentava o enunciado: "Você conhece os estereótipos que caracterizam pessoas nascidas em outros estados do Brasil?", seguido de três frases com espaços para completar: "Baianos fazem tudo devagar Baianos são ; Paulistas gostam de trabalhar - Paulistas são ; Mineiros não se abrem para qualquer pessoa - Mineiros são "(ARANTES (coord.), 2018, $\mathrm{s} / \mathrm{p})^{32}$. O interesse dos estudantes foi materializado em frases como: "No Paraná as pessoas são muito fechadas"; "Eu gosto dos baianos. Eles falam engraçado", entre outras formulações sobre pessoas de outros lugares do Brasil. A partir dessas questões, surgiram perguntas e comentários com base no conhecimento que tinham de cidades de outros estados, onde passaram algum tempo e vivenciaram hábitos diferentes.

Vale ainda destacar que uma atividade posterior a essa que faz parte do material se propõe a discutir mais diretamente a questão dos estereótipos e se estrutura da seguinte maneira:

Estereótipo (ou clichê) é o conjunto de características presumidamente compartilhadas por pessoas, coisas ou categorias. Um estereótipo pode ter um sentido positivo, como, por exemplo, quando dizemos que o Brasil é o país do futebol. Porém, em geral, funciona como marca pejorativa e, por essa razão, é a base de funcionamento dos preconceitos. Você conhece outros estereótipos que funcionem como marcas positivas da coisa ou da pessoa à qual se referem? E estereótipos depreciativos? (ibid., 2018, s/p).

A partir da experiência da pesquisadora com os estudantes na aula em tela, é possível afirmar que as perguntas e os comentários feitos pelos estudantes durante essa aula materializaram os efeitos produzidos a partir de uma construção imaginária estereotipada, presente especialmente nos versos da canção introdutória, que na discursividade chamaram a atenção para a estabilização de sentidos sobre os cariocas, que, nesse caso, são significados apenas por "sentidos positivos" (ibid., 2018, s/p). Mas, como diz Revuz, "falar é sempre navegar à procura de si mesmo com o risco de ver sua palavra capturada pelo discurso do Outro ou pelos estereótipos sociais, pródigos em 'frases feitas'. Não é raro que esse navegar mude de direção" (REVUZ, 2006, p. 220). Nos versos da canção, esse novo direcionamento produz efeitos que aludem aos discursos sobre os refugiados quando ditos pelo outro; sentidos que são estereotipados

\footnotetext{
${ }^{32}$ A atividade completa pode ser acessada no material disponível em:
} https://editoracartolina.files.wordpress.com/2019/01/entre_nos.pdf. 
REVISTA X, Curitiba, volume 14, n.3,251-274, 2019.

“como marca pejorativa", distinguindo-os pelo "funcionamento dos preconceitos" (op. cit.).

Assim, é preciso pontuar que essa unidade do material acaba tendo potencial de criar/sedimentar estereótipos, se não for problematizada adequadamente, e isso aparece nas discussões levantadas pelos próprios estudantes acima mencionadas/focalizadas. Vemos, nesse caso, como

[...] o livro didático desempenha um papel extremamente importante na constituição do imaginário da cultura do outro, reforçando ou desconstruindo estereótipos e favorecendo uma maior ou menor identificação com outras culturas (DINIZ, STRADIOTTI e SCARAMUCCI, 2009, p. 290).

Entretanto, as questões levantadas durante a aula que descrevemos neste artigo abriram espaço para que a pesquisadora, professora voluntária nessa aula, levando em conta a vivência dos estudantes numa realidade cotidiana que não necessariamente os identifica com os sentidos produzidos pelos versos da canção, incentivasse discussões que possibilitassem a problematização de estereótipos. Se a atividade Carioquices apresenta problemas de construção, cabe ao professor, culturalmente sensível, utilizá-la de forma a problematizar/desconstruir estereótipos.

Esse perfil de professor poderia ser preparado conforme descreve Cavalcanti (2013), ao afirmar que, numa "visão de educação linguística ampliada",

[...] um curso de licenciatura neste mundo de diáspora, imigração e migração, de mobilidade social cada vez mais emergente, precisaria enfatizar a formação de um professor posicionado, responsável, cidadão, ético, leitor crítico, com sensibilidade à diversidade e pluralidade cultural, social e linguística, etc., sintonizado com o seu tempo, seja em relação aos avanços tecnológicos, seja em relação aos conflitos que causam qualquer tipo de sofrimento ou de rejeição a seus pares, lembrando que essas questões são cambiantes, fluidas assim como as construções identitárias nas salas de aula. Ou seja, as exigências seriam para uma formação complexa que focalizasse a educação linguística de modo sócio-histórico e culturalmente situado, que focalizasse também as relações intrínsecas e extrínsecas da língua estrangeira e da língua 1 do professor em formação (CAVALCANTI, 2011 apud CAVALCANT1 2013, p. 212)

Contudo, como dissemos anteriormente, a maioria dos professores voluntários que atuam nesse curso não têm formação específica para ministrar aulas de português, sendo escolhidos por sua disponibilidade de tempo e pelo conhecimento das línguas mediadoras que são utilizadas em sala de aula. De acordo com os requisitos divulgados 
REVISTA X, Curitiba, volume 14, n.3,251-274, 2019.

pela Cáritas RJ nas chamadas para voluntariado ${ }^{33}$, esses critérios são suficientes para atender às expectativas do trabalho que vem sendo oferecido aos solicitantes de refúgio e refugiados atendidos por essa instituição.

Por tudo que relatamos acima, essas aulas, muitas vezes, funcionam como caixinhas de surpresa, nas quais

[...] o diálogo proposto [...] é competitivo, é tenso, é difícil. E não apenas porque o que está em jogo são relações de poder. É que diferenças de valores e de comportamentos podem ser, em muitos momentos, ininteligíveis ou inegociáveis. [...] Não se trata, portanto, de tentar escamotear a diferença, mas de se preparar para com ela conviver da forma mais informada e respeitosa possível.” (MAHER, 2007, p. 266-267 - negrito da autora).

Os professores voluntários levam propostas de atividades que, na maior parte dos casos, são bem recebidas e trabalhadas na íntegra com os alunos, mas, muitas vezes, os próprios refugiados trazem questões do cotidiano, exemplos de interações ocorridas nos dias próximos aos dias das aulas, anúncios escritos que não conseguiram compreender bem, coisas que ouviram e tampouco compreenderam, fatos que, se forem comuns à maioria, resultam num encaminhamento diferente do que tinha sido planejado pelos professores. É claro que compreendemos que essa é uma característica das práticas em sala de aula e não apenas das aulas de português para refugiados, mas, de acordo com a vivência da pesquisadora, corroborada na interação com os outros professores voluntários, esses eventos costumam acontecer com bastante frequência nas aulas do curso de português no qual ela vem realizando esse trabalho como professora voluntária nos últimos quatro anos. Lembramos que, em comparação com o ensino de outras línguas, esses estudantes de PLAc se encontram em um contexto de ensinoaprendizagem de imersão e isso modifica consideravelmente a experiência de troca e o conhecimento trazido para essa sala de aula.

\section{CONSIDERAÇÕES FINAIS}

À guisa de finalização, nesse artigo, apresentamos um histórico de dois projetos: (i) de ensino de português organizado pela Cáritas RJ e oferecido aos refugiados que se

${ }^{33}$ Curso de Português: ensino de português utilizando uma das línguas mediadoras: francês, inglês, espanhol ou árabe. As aulas ocorrem na UERJ, às segundas e sextas (turmas de falantes de espanhol) e às terças e quintas (turmas de falantes de francês e de inglês), das $9 \mathrm{~h} 30$ às 11h30. Não é necessário atuar nos dois dias da semana nem ter experiência de ensino, mas exige-se fluência na língua mediadora (itálicos nossos). Disponível em: http://www.caritas-rj.org.br/trabalhe-conosco.html. Acesso em: 26/01/2019; Voluntariado Professor(a) de Português - requisitos: fluência na língua mediadora que utilizará em sala de aula. Disponível em: $\underline{\text { http://www.caritas- }}$ ri.org.br/professordeportugues_ingles_frances.html. Acesso em: 18/02/2019. 
REVISTA X, Curitiba, volume 14, n.3,251-274, 2019.

encontram na cidade do Rio de Janeiro; e (ii) do programa da UERJ que resultou na elaboração do material didático publicado em 2018 para utilização nesse curso de português.

Reiteramos que nosso objetivo foi dar visibilidade a um trabalho que vem sendo realizado há tempos. Passar a visão desse projeto, sob a perspectiva da pesquisadora que, como professora voluntária na Cáritas RJ há quatro anos, vem observando e aprendendo com a construção do curso. Essa construção que se dá a partir dos esforços de todos os envolvidos, mas também de uma escuta além dos dizeres sobre refugiados que circulam nas instituições, na mídia, e de um olhar além dos estereótipos. Passar a visão, expandir a maneira de compreender, questionar, abrir-se para o diferente, sem, contudo, buscar o consenso, mas sim o diálogo que respeite a diferença e ganhe com ela.

Ao analisar a unidade didática com base no conceito de Interculturalidade na perspectiva de Maher (2007, p. 258), compreendemos que se trata de um desafio que não pode "ser entendido como um plus, como um enriquecimento, como um bônus porque o investimento no estabelecimento do diálogo, na capacidade de resolução do conflito intercultural é o alicerce, é o que justifica mesmo a existência” dessa prática de ensino. Como diz Maher:

[...] se antes as culturas estavam mais ilhadas e, por isso mesmo, mais protegidas, o fato é que a crescente urbanização, a intensificação dos movimentos migratórios, a globalização, a ampliação e a expansão vertiginosa dos meios de comunicação vêm, cada vez mais, expondo as culturas umas as outras. E é essa exposição que exige, sem mais adiamentos, que nos preparemos para o sempre difícil encontro com o outro, com o diferente. (MAHER, 2007, p. 258).

Como dissemos anteriormente, o que se propõe como diálogo intercultural é uma prática que possa colocar a diferença em discussão.

$\mathrm{Na}$ cidade do Rio de Janeiro, além do curso oferecido pela Cáritas RJ em parceria com a UERJ, há também outras iniciativas, entre elas o curso de Língua Portuguesa e Cultura Brasileira oferecido pelo Programa Nacional de Acesso ao Ensino Técnico e Emprego (PRONATEC) ${ }^{34}$ para imigrantes e refugiados e o curso de português para refugiados e migrantes promovido pela Secretaria de Estado de Direitos

\footnotetext{
${ }^{34}$ Disponível em: http://www.brasil.gov.br/cidadania-e-justica/2016/03/rio-oferece-curso-de-linguaportuguesa-para-imigrantes-e-refugiados. Acesso em: 17/02/2019.
} 
REVISTA X, Curitiba, volume 14, n.3,251-274, 2019.

Humanos e Políticas para Mulheres e Idosos (SEDHMI) e realizado pela Fundação de Apoio à Escola Técnica (FAETEC) ${ }^{35}$.

Outras cidades do Brasil oferecem o ensino de português para migrantes e refugiados, como é o caso de São Paulo, mas em boa parte dos casos a ação do Estado ainda é limitada, fazendo com que esse público conte mais com "o protagonismo de agentes da sociedade civil e do voluntariado" (BIZON e CAMARGO, 2018, p. 723). Entretanto, "como resultado de mobilizações horizontais, políticas voltadas a esse fim estão começando a se verticalizar em ações como a da Prefeitura Municipal e a do Instituto Federal de São Paulo" (id.); SEDHMI, FAETEC e UERJ no Rio de Janeiro; o Projeto Português Brasileiro Para Migração Humanitária (PBMIH) criado em setembro de 2013 pela Universidade Federal do Paraná (UFPR), cujos exemplos de contribuições estão publicados no livro intitulado Refúgio e Hospitalidade ${ }^{36}$, lançado pelo ACNUR em 2016; "e o Projeto de Pesquisa e extensão PROACOLHER: Português como Língua de acolhimento em contexto de imigração e refúgio, desenvolvidos na Universidade de Brasília (UnB), desde 2013” (GEDIEL e GODOY, 2016, p. 322) que “[...] ocorre nas dependências do NEPPE (Núcleo de Ensino e Pesquisa em Português para Estrangeiros)" (ibid., p. 326).

Quando propomos "passar a visão", pensando essa interação entre Cáritas RJ e UERJ, buscamos dar visibilidade a uma iniciativa não governamental, em curso há muito tempo, que ao longo dos últimos anos passou a contar com o apoio do Estado. A parceria com essa universidade desenhou contornos distintos aos trabalhos realizados pela Cáritas RJ. Por outro lado, a UERJ também ganhou maior visibilidade com a assinatura da Cátedra Sérgio Vieira de Mello e a oportunidade de "contribuir com a integração de refugiados" (ARANTES (coord.), 2018, s/p) e inspirar "novos diálogos, outros circuitos e muitos deslocamentos produtivos" (id.).

\section{REFERÊNCIAS}

ANUNCIAÇÃO, R. F. M. de. A língua que acolhe pode silenciar? Reflexões sobre o conceito de "Português como Língua de Acolhimento". Revista X. Curitiba, volume 13, n. $1, \quad$ p. $35-56, \quad 2018.2$ Disponível em: https://revistas.ufpr.br/revistax/article/view/60341/36627. Acesso em: 01/02/2019.

\footnotetext{
${ }^{35}$ Disponível em: http://agenciabrasil.ebc.com.br/direitos-humanos/noticia/2018-08/refugiados-emigrantes-que-estao-no-rj-poderao-ter-aulas-de. Acesso em: 17/02/2019.

${ }^{36}$ Disponível em: https://www.acnur.org/portugues/wpcontent/uploads/2018/02/Livro_Ref\%C3\%BAgio_e_Hospitalidade_2016.pdf . Acesso em: 20/05/2019.
} 
REVISTA X, Curitiba, volume 14, n.3,251-274, 2019.

ARANTES, P. (Coord.). Entre nós: português com refugiados. Rio de Janeiro, RJ: Cartolina, 2018.

Disponível https://editoracartolina.files.wordpress.com/2019/01/entre_nos.pdf. 23/01/2019.

BBC Brasil. 'Não imaginava que fosse dormir com fome no Brasil', diz refugiada do Congo. Da BBC Brasil no Rio de Janeiro. Publicado em 13/03/2013. Disponível em: https://www.bbc.com/portuguese/celular/noticias/2013/03/130311_refugiados_depoime ntos_cq.shtml. Acesso em: 17/03/2015.

BIZON, A. C. C.; CAMARGO, H. R. E. Acolhimento e ensino da língua portuguesa à população oriunda de migração de crise no município de são Paulo: por uma política do atravessamento entre verticalidades e horizontalidades. In: BAENINGER, R; et al. (Orgs). Migrações Sul-Sul. Campinas, SP: Núcleo de Estudos de População "Elza Berquó” - Nepo/Unicamp, 2018. p. 712-726.

BIZON, A. C. Narrando o exame Celpe-Bras e o convênio PEC-G: a construção de territorialidades em tempos de internacionalização. Tese (Doutorado em Linguística Aplicada) - Instituto de Estudos da Linguagem, Universidade Estadual de Campinas. Campinas, SP: [s.n], 2013.

CALCANHOTO, A. Cariocas. Rádio Vagalume FM. Disponível em: https://www.vagalume.com.br/adriana-calcanhoto/cariocas.html . Acesso em: 25/01/2018.

CAVALCANTI, M. C. Educação linguística na formação de professores de línguas: intercompreensão e práticas translíngues. In: Moita Lopes, Luiz Paulo. (Org.). Linguística Aplicada na Modernidade Recente - Festschrift para Antonieta Celani. São Paulo: Parábola, 2013, p. 211-226.

CENTRO RIO DE SAÚDE GLOBAL. UERJ abriga a Cátedra Sérgio Vieira de Mello. Disponível em: http://centroriosaudeglobal.org/?page_id=1395. Acesso em: 15/02/2019.

CORACINI, M. J. A celebração do outro: arquivo, memória e identidade: línguas (materna e estrangeira), plurilinguismo e tradução. $2^{\text {a }}$ ed. Campinas, SP: Mercado de Letras, 2013[2007].

CURSO DE PORTUGUÊS CÁRITAS/RJ. Formulário para relatório das aulas de português oferecidas pela Cáritas-RJ. Disponível em: https://docs.google.com/forms/d/e/1FAIpQLSf9wvhUQpLOYgNDMpGupY2AB7s_pv 88Li686ulTsn2bDZjQnw/viewform. Acesso em: 21/05/2019.

DINIZ, L. R. A.; STRADIOTTI, L. M.; SCARAMUCCI, M. V. R. Uma análise panorâmica de livros didáticos de português do Brasil para falantes de outras línguas. In: CRISTOVÃO, V. L. L.; DIAS, R. (Org.), O livro didático de língua estrangeira: múltiplas perspectivas. Campinas: Mercado das Letras, 2009, p. 265-304.

EBC. Número de refugiados bate novo recorde e atinge 68,5 milhões. Agência Brasil. Publicado em 19/06/2018. Disponível em: http://agenciabrasil.ebc.com.br/internacional/noticia/2018-06/numero-de-refugiados- 
REVISTA X, Curitiba, volume 14, n.3,251-274, 2019.

bate-novo-recorde-e-atinge-685-milhoes. Acesso em: 21/01/2019.

. Refugiados e migrantes que estão no RJ poderão ter aulas de português. Agência Brasil. Publicado em 25/08/2018. Disponível em: http://agenciabrasil.ebc.com.br/direitos-humanos/noticia/2018-08/refugiados-emigrantes-que-estao-no-rj-poderao-ter-aulas-de. Acesso em: 17/02/2019.

GEDIEL, J. A. P.; GODOY, G. G. de (Orgs.). Refúgio e Hospitalidade. Curitiba: Kairós Edições, 2016. Disponível em: https://www.acnur.org/portugues/wpcontent/uploads/2018/02/Livro_Ref\%C3\%BAgio_e_Hospitalidade_2016.pdf . Acesso em: 20/05/2019.

GOV BR. Rio oferece curso de língua portuguesa para imigrantes e refugiados. Publicado em 30/03/2016. Modificado em 23/12/2017. Disponível em: http://www.brasil.gov.br/cidadania-e-justica/2016/03/rio-oferece-curso-de-linguaportuguesa-para-imigrantes-e-refugiados. Acesso em: 17/02/2019.

IKMR. Em busca de paz e emprego, refugiados somam 5 mil no Brasil. América Diário Global. Publicado em 18/12/2013. Disponível em: http://www.ikmr.org.br/2013/12/embusca-de-paz-e-emprego-refugiados-somam-5-mil-no-brasil/. Acesso em: 17/03/2015.

JUNQUEIRA, C. "Vou passar a visão”. Como Sabiá se tornou tão popular dentro e fora da novela. VIX. 2017. Disponível em:

http://www.purepeople.com.br/midia/jonathan-azevedo-emplacou-passa-avisao_m2274182. Acesso em: 26/12/2017.

LOPEZ, A. P. A. Subsídios para o planejamento de cursos de Português como Língua de Acolhimento para imigrantes deslocados forçados no Brasil. Dissertação (Mestrado em Linguística Aplicada) - Faculdade de Letras, Universidade Federal de Minas Gerais, Belo Horizonte, 2016.

LOPEZ, A. P. A. e DINIZ, L. R. A. Iniciativas Jurídicas e Acadêmicas Brasileiras para o Acolhimento de Imigrantes Deslocados Forçados. Revista SIPLE. Ed. 9. 2018.

Disponível em:

http://www.siple.org.br/index.php?option=com_content\&view=article\&id=370:iniciativ as-juridicas-e-academicans-brasileiras-para-o-acolhimento-de-imigrantes-deslocadosforcados-\&catid=79:edicao-9\&Itemid=117. Acesso em: 01/02/2019.

MAHER, T. M. A Educação do Entorno para a Interculturalidade e o Plurilinguismo, In: KLEIMAN, A. B. e CAVALCANTI, M. C. (Orgs.). Linguística Aplicada - suas faces e interfaces. Campinas: Mercado de Letras, 2007, p. 255-270.

MOTA, K. M. S. Incluindo as diferenças, resgatando o coletivo- novas perspectivas multiculturais no ensino de línguas estrangeiras. In: MOTA, K. M. S.; SCHEYERL, D. (Orgs.). Recortes Interculturais na sala de aula de língua estrangeira. Salvador: EDUFBA: Instituto de Letras, Departamento de Letras Germânicas, 2004, p. 35-60.

PARES CÁRITAS RJ. Programa de Atendimento a Refugiados e Solicitantes de Refúgio. Disponível em: http://www.caritas-rj.org.br/quem-somos.html. Acesso em: 26/01/2019. 
REVISTA X, Curitiba, volume 14, n.3,251-274, 2019.

Trabalho e voluntariado. Disponível em: http://www.caritasri.org.br/trabalhe-conosco.html . Acesso em: 26/01/2019.

Voluntariado. Professor(a) de Português. Disponível em: http://www.caritasrj.org.br/professordeportugues_ingles_frances.html. Acesso em: 18/02/2019.

REVUZ, C. A língua estrangeira entre o desejo de um outro lugar e o risco do exílio. In: SIGNORINI, I. (Org.). Língua(gem) e identidade. Campinas: Mercado das Letras, 2006, p. 213-230.

RIZENTAL, S. S. Refugiados: tensões em um imaginário de acolhimento. Dissertação (Mestrado em Estudos de Linguagem) - Instituto de Letras, Universidade Federal Fluminense. Niterói, RJ, 2017. Disponível em: https://app.uff.br/riuff/bitstream/1/3843/1/Disserta\%C3\%A7\%C3\%A3o\%20Final.pdf. Acesso em: 23/01/2019.

UFPR. IX Seminário Nacional da Cátedra Sérgio Vieira de Mello - ACNUR / III Conferência Latino-Americana sobre Refúgio, Migração e Apatridia. Programação. 2018. Disponível em: http://www.ppgd.ufpr.br/wpcontent/uploads/2018/09/programacao-gts.pdf. Acesso em: 23/01/2019.

UNHCR ACNUR BRASIL. Deslocamento forçado supera 68 milhões de pessoas em 2017 e demanda novo acordo global sobre refugiados. 19/06/2018. Disponível em: https://www.acnur.org/portugues/2018/06/19/mais-de-68-milhoes-de-pessoas-

deslocadas-em-2017-e-essencial-um-novo-acordo-global-sobre-refugiados/. Acesso em: 21/01/2019.

2009 Global Trends. Disponível em:

https://www.unhcr.org/statistics/country/4c11f0be9/2009-global-trends-refugeesasylum-seekers-returnees-internally-displaced.html. Acesso em: 21/01/2019.

Dados sobre refúgio no Brasil. 2018. Disponível em: https://www.acnur.org/portugues/dados-sobre-refugio/dados-sobre-refugio-no-brasil/.

Acesso em: 22/01/2019.

Solicitações de refúgio por ano (2010-2016). In: Refúgio em Números. 2018. Disponível em: https://www.acnur.org/portugues/wp-content/uploads/2018/01/refugioem-numeros-2010-2016.pdf. Acesso em: 23/01/2019.

Cátedra Sérgio Vieira de Mello. Disponível em: https://www.acnur.org/portugues/2017/03/16/uerj-e-fundacao-casa-rui-barbosa-sao-asmais-novas-integrantes-da-catedra-sergio-vieira-de-mello/. Acesso em: 15/002/2019.

UNICAMP. Entrevista com a professora Itacira Araújo Ferreira. Disponível em: http://www.unicamp.br/ matilde/entrevista_itacira.html. Acesso em: 16/02/2019. 